\title{
Living with Vesico-Vaginal Fistula at Jimma University Medical Centre: A Phenomenological Study
}

\author{
Yasmin Mohammed \\ Department of Psychology, Jimma University, Ethiopia \\ Email: yasminmohammed448@gmail.com
}

http://dx.doi.org/10.18415/ijmmu.v5i5.531

\begin{abstract}
Obstetric fistula leaves women with few opportunities to earn a living and worsens their poverty. The death of the baby, inability to carry a child, and the stigma that accompanies fistula results in significant emotional \& psychosocial damage. Vesico-vaginal fistula (VVF) is a medical condition that involves an abnormal opening between the bladder and the vagina, leading to uncontrolled leakage of urine which is resulted mostly from an unattended prolonged labor. Semi-structured in-depth interview was used to explore the lived in experience of eight women with obstetric fistula who were admitted in Jimma University Medical Center selected by purposive sampling technique. The data were analyzed using thematic analysis. Seven themes illustrating the lived in experiences of women with Vesico-vaginal fistula were emerged. These were awareness of altered identity, depression, anxiety, marital problems, disrupted social life, economic problems and coping strategy. Problem focused coping strategies mentioned were having family support, orientating to reality, financial independence and religiousness. Emotion focused coping strategies were also noted, such as, isolation, suicidal thoughts and anger. Altered psychological, physical, social and economic functioning were some of the disruption in the life of women with VVF observed. Promoting their positive coping strategies, providing physical and psychological support is crucial to reverse debilitating effects of women with VVF.
\end{abstract}

Keywords: VVF; Lived Experience; Psychosocial; Economic Problems; Jimma University Medical Center

\section{Introduction}

Women's health status varies widely across the globe. Women in developing countries are challenged with a myriad of socio-economic and cultural factors which critically affect their health.

One of the indicators of maternal health is maternal mortality rate. Worldwide, approximately 800 women die every day from preventable causes related to pregnancy and childbirth. In 2010, about 287,000 women died worldwide during and following pregnancy and childbirth (WHO., 2010).

The development of obstetric fistula is directly linked to one of the major causes of maternal mortality: obstructed labor. It occurs in about $5 \%$ of pregnancies and accounts for $8 \%$ of maternal deaths 
(UNFPA., 2012). Although obstetric fistula has been virtually eliminated in many developed countries, it continues to afflict many poor women and girls worldwide who do not have access to health services. The most frequently reported global prevalence of obstetric fistula shows that approximately 2 million women have untreated fistula and approximately 100,000 women develop fistula each year. Other estimates show that as many as 130, 000 new cases of obstetric fistula are occurring annually in Africa and globally up to 3.5 million women may be living with the condition (WHO., 2015).

Describing it as the most devastating of all pregnancy-related disabilities, the United Nations Population Fund (UNFPA) says obstetric fistula affects an estimated 50,000 to 100,000 women around the world every year and is particularly common in sub-Saharan Africa, where populations face challenges to obtaining quality health care (UNFPA., 2012). The World Health Organization (WHO) estimates that at least 9,000 Ethiopian women develop new obstetric fistulas every year (WHO., 2015).

Vesico-Vaginal Fistula (VVF) is a cause for long term morbidity arising out of poor obstetric care. The stigma associated with VVF makes it difficult to accurately estimate the prevalence (Ouj \& Emma- Echiegu., 2015). Estimates suggest that at least 3 million women in poor countries have unrepaired vesico-vaginal fistulas, and that 30 000-130 000 new cases develop each year in Africa alone and 262,000 of the cases of fistula are in sub-Saharan Africa (WHO., 2015). Ethiopia had about 142,387 VVF cases in 2013 (Biadglign., Laqew., Reda \& Deribe., 2013).

The problem of obstetric fistula is deep rooted in the social, cultural and psychological environment of a society. Harmful traditional practices such as early marriage, sexual abuse have relation with the occurrence of fistula (UNFPA., 2012). Poor nutrition and heavy workload also exacerbates the problem by affecting development of stature. In many least developed countries obstetric fistula continues to affect the most marginalized member of the population that is the poor, young, illiterate girls and women in rural regions (UNFPA., 2012).

The major consequences of VVF include urinary incontinence, stigma and discrimination including: abandonment, not allowed eating with family members, not participating in social events and gatherings and others. Because of the social exclusion, they lose their self-esteem, prefer to hide from society's view, have adverse feelings about the problem and develop suicidal ideas. Even after treatment, it is difficult for some women to fully enjoy family and community life. Divorce and ostracization are attributed as direct consequences of bad odor arising from incontinence (WHO., 2015).

Worldwide different researches on obstetric fistula have been conducted for more than 40 years. These researches have focused mainly on the availability, accessibility, and utilization of services (Yenenesh., 2014). In Ethiopia vesico-vaginal fistula is a serious social and health problem, never the less the existing literatures focus mainly on the magnitude of the problem, its etiology, and the surgical treatment that can be delivered (WHO., 2015) and limited research has been done to explore the personal experience of women with VVF, focusing on their perception of life after developing a VVF and the ensuing problems arising due to this health condition. Especially little attention has been given to investigate its devastating psychosocial consequences especially in South West Oromia region. Accordingly, the purpose of this study was to describe and interpret the common shared meanings of living with VVF from the perspective of women admitted with this obstetric condition at JUMC. Specifically it aims at exploring how the occurrence of VVF affected the women's identity, understanding the psychological problems of women with VVF admitted in JUMC, identifying the socio cultural problems of women with VVF admitted in JUMC and exploring the coping mechanisms women with VVF use to deal with their problems. 


\section{Material and Methodology Study Setting and Study Design}

The study was conducted at Jimma University Medical Center in Jimma town of Ethiopia. The hospital offers different specialty services. The obstetrics and gynecology specialty department has 75 beds of which 24 beds are reserved for gynecology patients.

A qualitative approach using Colaizzi’s (1978) descriptive phenomenological research design was used with the intention of getting the women participants to talk about their psychological and socio cultural challenges of having to live with VVF, the coping mechanisms they use to deal with these problems and how having to live with VVF has shaped their identities.

Sampling and Data Collection: Eight women admitted with VVF were included in the study by using purposive sampling. The interview was conducted in Afan-Oromo language. Audio -recording and field notes on the non-verbal communication were made with permission from the interviewees. Each interviewee was assigned a code, for example Participant 1, April 26 2017. Each interview lasted approximately 60 minutes. As soon as possible after each interview the researchers listened to the recording and made notes and transcribed key words, phrases and statements in order to allow the voices of research participants/informants to speak.

Ethical Consideration: Prior to the conduct of study ethical clearance was obtained from relevant bodies in the institution as well as informed consent from the women who were willing to participate in the study. The women were also assured about the confidentiality of their response and it would be used only for the purpose of this study

\section{Data Analysis}

As the first step of analysis the qualitative data from the interviews were transcribed verbatim and translated from Afan Oromo to Amharic language then to English by three individuals who are fluent speakers of Afan Oromo and Amharic language and another person back-translated the two transcripts to Afan Oromo to ascertain the quality of the translation. The following steps represent Colaizzi's process for phenomenological data analysis used in this study. The investigators bracketed their ideas, assumptions, and prejudices such as 'VVF occur only to very young women, women with fistula are irritable and have animosity or they deny the occurrence of psychosocial problems'.

In the stage of intuiting, the researchers remained open to the meanings attributed to the phenomenon, by those who have experienced it. For process of data analysis each transcript was read and re-read in order to make sense about the entire content. The written observations of the non-verbal communication of each participant were used to corroborate the transcribed phrases and words from individual audio-recording. From each transcript significant statements /phrases pertaining to the experience of living with VVF were extracted, which were then written on a sheet of paper and coded based on their occurrence by transcript page and line numbers. Formulated meanings were then derived from these significant statements. Forty formulated meanings were developed.

The next step involved grouping these formulated meanings into categories and themes. All these categories and themes were integrated to make a meaningful description of the women's lived experience .Finally the whole structure of the phenomenon was extracted. Eventually the findings were validated with the research participants to compare the researchers' descriptive results with their experiences. 


\section{Result}

As indicated in Table 1, the 8 women interviewed in this study were between 17-40 years of age. Six were illiterate and only 2 had education up to primary education level. 4 respondents were farmers, 1 was daily laborer, 2 were merchants and one was homemaker. Four informants were divorced, two were separated, and two were widowed. Concerning the age of their first marriage and pregnancy, seven of them got married at the age less or equal to 18 and got pregnant that same year or one year after their marriage. Seven of the women interviewed had still births.

Table1 The Socio-demographic characteristics of the participants

\begin{tabular}{|c|c|c|c|c|c|c|c|c|c|c|c|}
\hline \multirow{2}{*}{$\begin{array}{l}\text { Partici } \\
\text { pants }\end{array}$} & \multirow{2}{*}{$\begin{array}{l}\text { Age, } \\
\text { in } \\
\text { years }\end{array}$} & \multirow{2}{*}{$\begin{array}{l}\text { Educati } \\
\text { onal } \\
\text { level }\end{array}$} & \multirow{2}{*}{$\begin{array}{l}\text { Marita } \\
1 \\
\text { status }\end{array}$} & \multirow{2}{*}{$\begin{array}{l}\text { Occupati } \\
\text { on }\end{array}$} & \multirow{2}{*}{$\begin{array}{l}\text { Monthly } \\
\text { Income } \\
\text { in Birr }\end{array}$} & \multirow{2}{*}{$\begin{array}{l}\text { Age } \\
\text { at } \\
1^{\text {st }} \\
\text { marri } \\
\text { age }\end{array}$} & \multirow{2}{*}{$\begin{array}{l}\text { Age at } \\
1 \text { st } \\
\text { pregna } \\
\text { ncy }\end{array}$} & \multirow{2}{*}{$\begin{array}{l}\text { Age at } \\
\text { the } \\
\text { occurren } \\
\text { ce of } \\
\text { VVF }\end{array}$} & \multicolumn{3}{|c|}{ No of children } \\
\hline & & & & & & & & & $\begin{array}{l}\text { ali } \\
\text { ve }\end{array}$ & $\begin{array}{l}\mathrm{de} \\
\mathrm{ad}\end{array}$ & $\begin{array}{l}\text { Still- } \\
\text { birth }\end{array}$ \\
\hline 1. & 22 & Grade 7 & $\begin{array}{l}\text { Divor } \\
\text { ced }\end{array}$ & Merchant & 1200 & 18 & 18 & 21 & 0 & 0 & 2 \\
\hline 2. & 22 & Grade 7 & $\begin{array}{l}\text { Separ } \\
\text { ated }\end{array}$ & Farmer & Not sure & 17 & 18 & 21 & 1 & 0 & 1 \\
\hline 3. & 35 & Illiterate & $\begin{array}{l}\text { Wido } \\
\text { wed }\end{array}$ & Farmer & Not sure & 15 & 16 & 16 & 0 & 0 & 1 \\
\hline 4. & 26 & Illiterate & $\begin{array}{l}\text { Divor } \\
\text { ced }\end{array}$ & $\begin{array}{l}\text { Daily } \\
\text { laborer }\end{array}$ & 500 & 15 & 16 & 16 & 1 & 1 & 0 \\
\hline 5. & 40 & Illiterate & $\begin{array}{l}\text { Wido } \\
\text { wed }\end{array}$ & $\begin{array}{l}\text { Home } \\
\text { maker }\end{array}$ & Not sure & 17 & 18 & 18 & 0 & 0 & 1 \\
\hline 6. & 17 & Illiterate & $\begin{array}{l}\text { Separ } \\
\text { ated }\end{array}$ & Farmer & Not sure & 15 & 16 & 16 & 0 & 0 & 1 \\
\hline 7. & 35 & Illiterate & $\begin{array}{l}\text { Divor } \\
\text { ced }\end{array}$ & Merchant & 300 & 15 & 16 & 16 & 1 & 0 & 1 \\
\hline 8. & 25 & Illiterate & $\begin{array}{l}\text { Marri } \\
\text { ed }\end{array}$ & Farmer & Not sure & 23 & 24 & 24 & 0 & 0 & 1 \\
\hline
\end{tabular}

\section{Experiences of Living with Obstetric Fistula}

Having to live with an unrepaired VVF, results in morbidity, constant wetness, odor, skin excoriations and discomfort cause social alienation. Further in societies where marital success is primarily based on sexual relationship and child bearing role of the woman, having to live with VVF has a detrimental influence on their identity as revealed through discussion with the participants. Based on the verbatim of the participants significant statements were extracted, meanings were formulated for the significant statements. Finally the meanings were clustered in to seven themes as indicated below in Figure 1. Each theme will be discussed in turn and demonstrated by direct quotations from transcripts. In the extracts three dots (...) indicates omitted text. 


\section{Theme 1. Altered personal identity}

Low self-worth, Constant guardedness and fear, Awareness in role incompetence

Theme 2. Depr ession

Physiological changes, Withdrawing to Self, Grief over loss of health, Mood changes, Death wish

\section{Theme 3. Anxiety}

Preoccupation with illness, Problem of sleeping, physical symptoms of anxiety, Social anxiety

\section{Theme 4. Marital problem s}

Problematic sex life, communication problem, disrupted marriage

Theme 5. Disrupted social life

In ability to attend social events, Social discrimination

Theme 6. Economic problems

Economic liability, Deteriorated work performance, Additional expenses

Theme 7. Coping strategy

Problem focused, emotion focused

Fig1. Demonstration of themes

\section{Theme 1. Altered Personal Identity}

Obstetric fistula is a condition which affects every life aspect of the women involved. In this study the participants stated that because of the VVF they generally feel inferior and lost the essence of their identity as women: their self-worth. Concerning this, the interviewees put their situation as follows:

“...I believe I am good for nothing ... I don't have anything that I'm proud of!! "( P5, 40 years, lived with VVF for 22 years).

"I believe I am inferior to other people, I am not as good as people..." (Participant 2, 22 years, lived with VVF for 1 year).

"When I think about my life after my illness, all I wish is spending time with people just like my friends, be equal as my friends, I wish I were healthy like them and work like them. I feel sad all the time because it doesn't matter if I have beautiful cloths since my situation makes it difficult to wear them" (P4, 26 yrs, lived with VVF for 9 yrs). 
For some of the interviewees after the occurrence of the VVF, the society's words and reaction towards their illness made them to be with constant guardedness and fear.

"Most of the time I am busy of worrying about what others think of me. People don't say anything out loud but I worry a lot what they may have said" (P1, 22 yrs, lived with VVF for one year).

"How could I stand in front of others? I am afraid of that!!!" (P6, 17 yrs, lived with VVF for one year).

"I don't go with people. If there is a place to visit, I don't go!!I just stay home!!I am afraid of being with people" (P7, $35 \mathrm{yrs,} \mathrm{lived} \mathrm{with} \mathrm{VVF} \mathrm{for} 19 \mathrm{yrs})$.

On the other hand, the participants revealed that one of the factors which altered their personalities was awareness in role incompetence as a mother and a wife.

"I worry about not having children" (P3, 35 yrs, lived with VVF for 19yrs)

“... there is no sexual contact between us since my problem...(Participant 2, 22 years, lived with VVF for 1 year).

\section{The Psychological Problems Faced by the Women with VVF Theme 2. Depression}

The women interviewed stated that ever since they knew they have continuous leakage of urine, it was difficult for them to eat, to sleep and to talk to people.

“I decreased eating, ... and I don't sleep well as before... "(Participant 2, 22 years, lived with VVF for 1 year).

“... I don't speak to people” (P1, 22 yrs, lived with VVF for one year)

Grief over loss of heath was inevitable for the women interviewed. One participant put her situation in this way:

“When I think about my illness... and worry for not being healthy...” (P3,35 yrs, lived with VVF for $19 \mathrm{yrs})$.

Besides the physiological changes, in some of the participants, mood changes were observed.

"After I delivered dead baby and this illness happened to me, I was not able to stand or sit for many months. I did not eat anything almost for two months, I could not stop yelling and crying and when I urinate I had burning sensations. So people usually gather around when they hear my screaming and crying. ..." (Participant 5, 40 years, lived with VVF for 22 years).

The sense of unworthiness these women felt and when things getting worse some of the interviewee thought of ending their life.

"...I have thought of taking my life many times before when things got worst" P5, 40 years, lived with VVF for 22 years).

"When I get angry, the thought of not becoming alive comes to my mind" (P1, 22 yrs, lived with VVF for one year). 


\section{Theme 3. Anxiety}

The women interviewed explained that in their everyday life they had to worry about many things like how long their life would continue in the future with the leakage of urine and the bad smell it caused:

“... I still worry about my illness a lot. I worry what if I don't get well" (P1, 22 yrs, lived with VVF for one year,).

The women also had to worry about the society's perception and treatment towards them because of their illness.

"I worry about people knowing my illness. People think I am still menstruating and they ask me why my menses is not stopping and I don't tell them what really is happening to me. If I tell them, I know they will insult me. So I keep my mouth shut" (Participant 2, 22 years, lived with VVF for 1 year,).

For some of the participants different physiological symptoms of anxiety was evident.

"Generally, when I think of my illness, I feel my blood going through my vein and it seems like my body parts being tied up with something" (P1, 22 yrs, lived with VVF for one year).

"Still now when I think of my illness my world start to turn up side down, my heart beats fast like a drum being beaten quickly" ( participant 5, 40 years, lived with VVF for 22 years )

For the others, thinking about the illness itself, societal attitude and reaction towards their illness made them to develop social anxiety including becoming angry and hostile toward others.

"Generally when I think of my illness, above everything else the anger I felt is even worst" (P1, 22 yrs, lived with VVF for 1year).

"When I think about my illness, my mind stops working. The illness makes people angry. Especially when people say bad things and insult me, I get very angry to the extent that I might not know what I responded to them" (P4, 26 yrs, lived with VVF for 9 yrs).

Half of the women interviewed described they either have difficulty of sleeping or have nightmare after the occurrence of the VVF.

“I don't have night mares because I don't sleep at all!" (P1, 22 yrs, lived with VVF for one year).

"Yes, I have night mare sometimes" (P4, 26 yrs, lived with VVF for 9 yrs).

\section{The Socio-Economic Problems Faced by the Women with VVF Theme 4. Marital Problems}

Among many of the marital problems which contribute to marital dissolution are problematic sex life and poor communication between the spouses. Hence some of the interviewees put their situation in the following way.

"My husband was very unhappy with my illness and got angry because we were not having sex. We started arguing all the time about everything and when he finally was fed up of the arguments we had, he married another woman and divorced me" (P4, 26 yrs, lived with VVF for $9 \mathrm{yrs})$. 
“...there is no sexual contact between us since my problem. That's why he sent me to my parents' house" (Participant 2, 22 years, lived with VVF for 1 year, the sadness she felt was obvious on her face because of the this happening).

The women also mentioned that after their illness, they were either forced or force themselves to go back to their parents, and for those who were not divorced. They explained what happened to their marital life as follows:

"After I delivered my child at my mother's house and after two days when I knew I have continuous leakage of urine, I didn't go back to my husband's house. I stayed with my mother. I told my husband that I was sick and I couldn't be his wife anymore without specifically telling him what kind of illness I have. No one also told him what my illness is either. So when he became tired of asking me over and over again to come back, we got divorced" (P1, 22 yrs, lived with VVF for one year).

"... when I have learnt my illness I left him long time ago. Now he is married to another woman. I live with my mother now” (P7, 35 yrs, lived with VVF for $19 \mathrm{yrs})$.

\section{Theme 5. Disrupted Social Life}

The continuous leakage of urine and the bad odor comes along with it made it difficult for the women with VVF to socialize themselves at different occasions like coffee ceremony, weddings, funerals and other events with the society for fear of being insulted, being outcaste and spread rumors about them behind their back or even in front of them which has devastating impact on their overall psychological wellbeing. As a result, majority of the interviewees preferred staying at home or being isolated. They put this aspect of their life as stated below.

"I don't normally participate in casual events like drinking coffee with the neighbors and so on. In social gatherings, like when someone died comforting the family members and when the situation is required that I participate but still I have bad odor. Because of this bad smell, People insult me by saying she is dirty, has bad smell, she's unable to control her urine day and night, get away from her they say... When we go to the funeral, we cannot control our urine. So when our cloths get soaked with urine, every one covers their nose with their hand or with their cloths..." (P4, 26 yrs, lived with VVF for 9 yrs,).

"What can I say about what they say about me? How could you even ask? Even if they don't say it out loud in front of me, behind my back they say very hurtful things like she can't control her urine and so on..." (P3, 35 yrs, lived with VVF for 19yrs).

"Everyone around me knows my problem even if they don't say anything in front of me because the urine leakage is there all the time. It's obvious what they are thinking and saying behind my back because they express their thoughts none verbally by showing me how disgusted they are. Sometimes they say it out loud behind my back by saying how much I smell like urine. As a result don't participate in many social events" (Participant 5, 40 years, lived with VVF for 22 years).

\section{Theme 6. Economic Problem}

The participants of the study stated that their experience of continuous leaking of urine, the smell, feelings of shame, fear and sorrow affected their ability to earn a living through farming; petty business, peddling or employment. 
"To begin with because of my odor it's difficult to find job which suits me even at the daily laborer level because everyone hates me and no one wants to work with me". (P4, 26 yrs, lived with VVF for $9 \mathrm{yrs}$ )

"Because of my odor it's difficult for me to leave home let alone work. I stayed home and prepare coffee and food the others to come home. Currently I live with my sister who is also poor and has nothing. So we are living in extreme poverty to the extent that we couldn't afford buying not only soap but also the food that we eat..." (Participant 5, 40 years, lived with VVF for 22 years).

For those who were able work needed extra help to perform their jobs:

"Before my illness I used to work at the farm with my full potential with no or little help from others. But currently I am not able to do anything without getting support from my brother in law to perform the farming. He helps me ploughing the land and spreading the seeds and I try to do the rest of the work which require minimum effort. But still I cannot afford buying soaps to wash my cloths daily ..." (P3, 35 yrs, lived with VVF for 19yrs)

\section{Theme 7. Coping Mechanisms}

Participants used two general strategies, i.e., problem-focused and emotion-focused, for coping with everyday routines that were disrupted by their illness. Those who used problem focused coping utilized various constructive strategies and resources to reorganize their daily lives based on the nature of the event they experienced and the resources they had. This involved seeking family support, orientating to reality, becoming financially independent by working hard and having faith in their religion. Few of the participants explained their coping mechanisms in the following way:

"Even if there are people in my house who help me out, I still worry about my illness a lot... Whenever I cry, they try to comfort me by saying they will get me medical help that I shouldn't worry" (P1, 22 yrs, lived with VVF for one year).

"My mother is here with me to help me out" (Participant 2, 22 years, lived with VVF for 1 year).

"Having my son around me gave me the strength to survive until today" (P7, 35 yrs, lived with VVF for $19 \mathrm{yrs})$.

“What can I do unless my creator help me and heal me, I don't know ..." (P3, 35 yrs, lived with VVF for 19yrs)

"Accepting the illness, praying and wishing that there will be a day where I would be better helped me to continue living my live until today" (P3, 35 yrs, lived with VVF for 19yrs).

On the other hands, those who used emotion focused coping mechanism whenever they experienced stressful events that were relatively tolerable, but not necessarily amenable to direct action, they used at least one emotion-focused coping strategy, i.e., isolating themselves or suffering in isolation, suicidal thoughts, venting of feelings like becoming angry, crying. Accordingly when those participants were asked their coping strategies, they replied in the following way:

"Ever since one of my neighbours said bad things to me, I never left home!!" (P6, 17 yrs, lived with VVF for one year). 
"I don't go with people. If there is a place to visit, I don't go!!I just stay home!!I am afraid of being with people" (P7, 35 yrs, lived with VVF for $19 \mathrm{yrs})$.

"... I believe I am good for nothing and I have thought of taking my life many times before when things got worst. I don't have anything that I'm proud of" (Participant 5, 40 years, lived with VVF for 22 years, with an absolute loss of self-worth she replied).

"Yes I get angry easily. When I think about what's going to happen to me with this illness I get angry" (P7, $35 \mathrm{yrs}$, lived with VVF for $19 \mathrm{yrs})$.

"When I think about my illness I cry day and night and worry for not being healthy and not having any children..." (P3, 35 yrs, lived with VVF for 19yrs)

\section{Discussion}

\section{Awareness of Altered Identity}

Obstetric fistula is a condition which affects every life aspect of the women involved. The individual, family, and social-cultural experiences women living with obstetric fistula go through fundamentally destroy these women's identity. The failures of the women to control urine, maintain their marriages, bear children, or participate in social economic activities make them lose the essence of their identity as women, wives, friends, and community members ;their self-worth. Many women who are affected by obstetric fistula lost their babies during the birthing process (Mselle \& Kohi., 2015). When this happens, they basically lose the essence of their identity; their self-worth. In this study all of the participants lost their babies during the birthing process. And majority of them felt as losers because they don't have children or good health and they believed that they don't have anything they are proud of. The bad odor they have is also one of the main reasons for them to be socially discriminated and to lead their life in shame and disgrace. As a result some of the women with VVF developed fear of being with people while the others become suspicious of people and started spending time worrying what people might have said or think even if no one said anything. In addition they explained that the feeling of uselessness and the feeling of inferiority they felt because they are not able to do what others do and unable to think of having good quality made them feel like they are nothing.

\section{Depression}

The medical and social consequences of obstetric fistula are distressing and can have a profound effect on psychiatric health. Women affected by fistula who have been shunned and isolated typically experience intense feelings of shame, self-loathing, and depression. These depressive feelings may affect individual performance of daily activities; worsen interpersonal relationships, and even lead to selfneglect and suicidal thoughts (Yeahey., Chipeta., Taulo \& Tsui., 2019. In this study it is found out that following the occurrence of the VVF, the psychological wellbeing of the women has altered. Losing their self-worth because of their disrupted social life, inability to fulfill marital role as a woman, inability to bear child, most women lost their motivation to lead their life eagerly as before as a result they manifested different behavioral changes like loss of appetite, sleep disturbances, becoming quit ,deteriorated work performance. When the different problems that they are facing become intolerable most of the women thought of ending their life. 


\section{Anxiety}

The participants of this study discussed that after the occurrence of the VVF they had to worry in their everyday life about many things like how long their life would continue in the future with the leakage of urine and the bad smell it caused. For some of the women, their anxiety is stemmed from their continuous worry about loss of ability to perform role of child bearing and being a wife. For the others, the source of worry was the society's perception and treatment towards them. The women explained the insults, the mockery, and the disgusted nonverbal facial expression, the rejection and the humiliation they face from the society made them to be frustrated and become impulsive towards others. They also mentioned they become angry for reasons like, thinking about the illness itself since they couldn't do anything either to stop the leakage or the bad odor from it. Accordingly, for some of the participants their anxiety was accompanied by different physical anxiety symptoms like palpitation, shortness of breath and muscle tension. In addition to that, half of the participants of the interview described that they either have difficulty of sleeping or have nightmare after the occurrence of the VVF.

\section{Marital Problems}

In many sub-Saharan countries women's identity is rooted from the values they get from their husbands and society through marriage. They gain sense of self-worth through their ability to bear children and fulfill their roles as women and wives (Mselle \& Kohi., 2015). Unfortunately living with uncontrollable leaking of urine and symptoms associated with it for many years prevent women from having sexual intercourse with their husbands and bearing children (Ahmed \& Tuncalp., 2015). In this study it is revealed -that Living with fistula for years, and the continuous leaking of urine and symptoms associated with it, prevented the women from having sexual contact with their husbands and as well affected the communication pattern of the couples. As a result, most women living with obstetric fistula frequently described rejection by their husbands and family members. The Women explained that the problem of fistula had separated them from their husbands because it limited their ability to fulfill marital roles. Accordingly most of the women who participated in the interview were divorced and the rest of the women if not divorced, were separated.

\section{Disrupted Social Life}

The women living with obstetric fistula experience a deep sense of loss that affected them as women and wives. The impairment caused by fistula produces disabilities that prohibit social participation and significantly reduce their possibilities to achieve their life goals. It bans women to participate in the social economic activities and thought that it was largely because of the bad smell, which prohibited other people to interact with them. Many lost their privilege of establishing and maintaining social networking, and could not gather with the rest of the society in social events (Ahmed \& Tuncalp., 2015). Similarly this study found out that the continuous leakage of urine and the bad odour comes along with it made it difficult for women with obstetric fistula to socialize themselves at different occasions like coffee ceremony, weddings, funerals and other events with the society for fear of being insulted or being outcaste. The participants of the study explained that they were constantly insulted, humiliated and get rejected by the members of the society. Even those who were not rejected, they isolated themselves for fear of being insulted or rejected. 


\section{Economic Problems}

Because of women's inability to restrain urine and the resulting smell, genital sores, discomforts, feeling of shame and stigma; women were not welcome to participated in socio-economic activities nor contribute to the family earnings and development as expected. Women were unable to work, or work to their capacity because fistula limited their chances to access jobs. Therefore, women could not earn an income through farming, business, hawker or employment. Studies have reported that women who were employed lost their jobs because of the condition (Ahmed \& Tuncalp., 2015). In this study some of the participants revealed that because of the continuous leakage of urine and the bad odor they have, they were very much humiliated to the extent that they barely left their home let alone work outside their home to earn income. Even those who managed to go outside their home to work, they either had difficulty of finding a job because of their bad smell or they couldn't manage working in the farm alone as before. As a result because of the deteriorated work performance, the income they earn has decreased which made some of them to live in absolute poverty. According to the participants response this study revealed that the common tiresome task they all shared was changing and washing of their cloths and their bodies which subjected them for additional expense of buying soap.

\section{Coping Mechanism}

To cope up with their the different problems they faced some of the participants used problem focused coping like seeking family support, orientating to reality, becoming financially independent by working hard and having faith in their religion whereas the rest used at least one emotion-focused coping strategy, i.e., isolating themselves or suffering in isolation, suicidal thoughts, venting of feelings like becoming angry, crying. Similarly, according to the transaction model of stress and coping, when people face challenges, they focus their efforts on emotions and problem solving. 18 Participants in this study made similar efforts to regulate their emotions through suicidal thoughts, avoiding family and community members, suffering in isolation, hiding their story and circumstances, accepting the changes associated with obstetric fistula, and positive subjective interpretation (Ahmed \& Tuncalp., 2015).

In general, based on the findings of the study, Figure 2 shows how living with VVF influences the life of a woman from different direction.

\section{Limitations}

This study has explored the experience of eight women who were admitted to the hospital by their family members for repair of the VVF. It is likely that women who are destined to live without getting any medical aid for this debilitating condition may have different experiences to share. Nevertheless, this study did not aim at transferability or generalizability of findings, but rather to understand and shed light on the experience of a woman living with VVF.

\section{Conclusion}

VVF is treatable but above all it is preventable. The impact of VVF is devastating for the woman. Every aspect of her life is affected. This study revealed the impact of living with VVF on her personal identity, psychological wellbeing, as well as socioeconomic aspect of life and the coping mechanisms. 
Dissemination of knowledge on obstetric care in the community, empowering women towards appropriate health care seeking behaviors and Promoting their positive coping strategies, provision of timely and adequate obstetric services are still the pressing needs in developing countries.

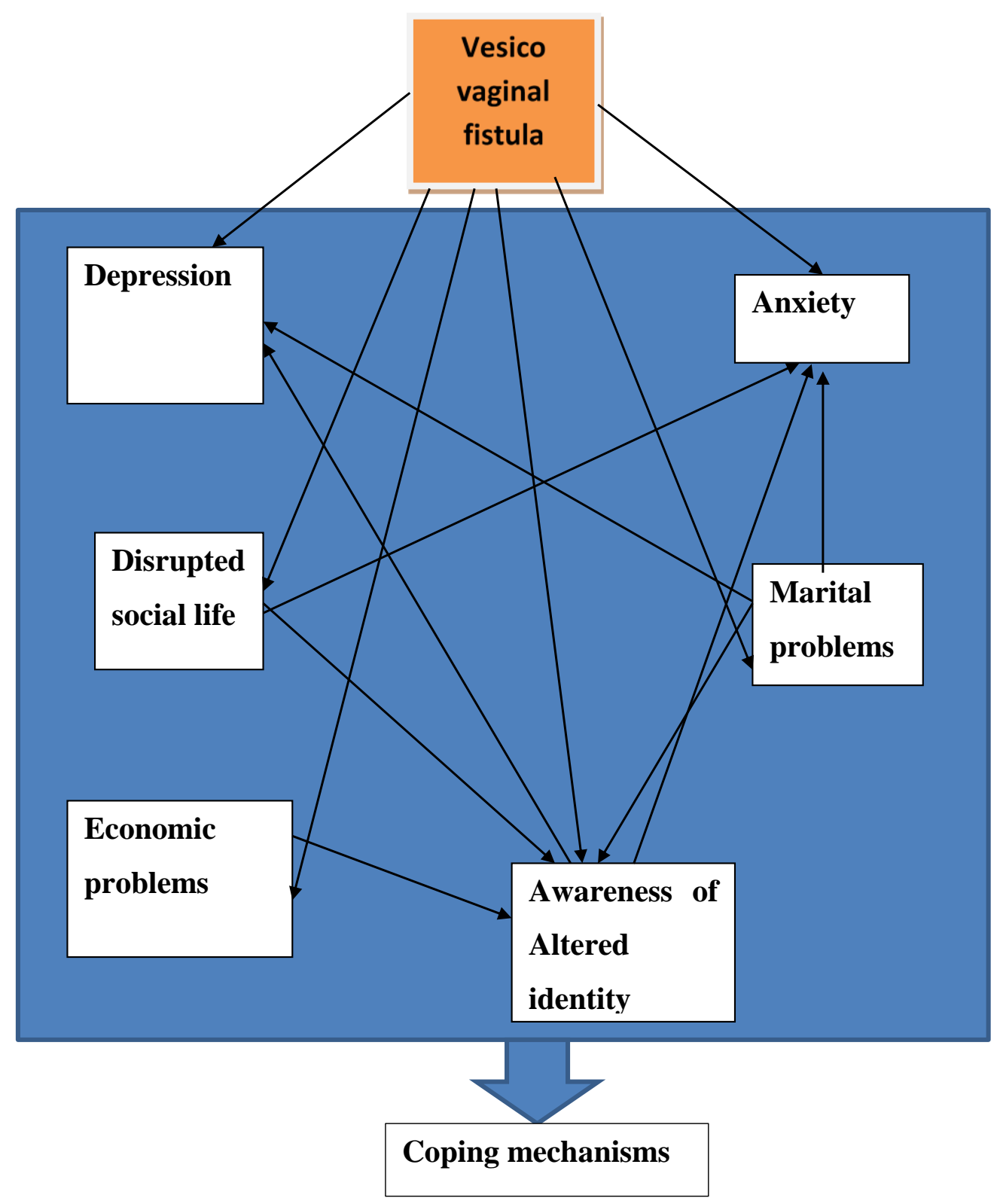

Fig. 2 Comprehensive conceptual framework how living with VVF influences the life of a woman Source: The author of this article 


\section{Acknowledgments}

The author of this study would like to thank all participants of the study and Dr Kalkidan Hassen for his constructive comments.

\section{Funding Statement}

This work is self-supported research

\section{Data Availability Statement}

The qualitative data from the in-depth interview used to support the findings of this study are included within the article.

\section{Conflict of Interest}

The author declares that there is no conflict of interest regarding the publication of this paper.

\section{References}

Ahmed S, Tunçalp Ö. (2015). Burden of Obstetric Fistula: from Measurement to Action. Lancet Glob Health, 3(5): e243-4. http://dx.doi.org/10.1016/S2214-109X(15)70105-1.

Biadgilign S, Lakew Y, Reda AA, Deribe K. (2013). A population-based Survey in Ethiopia Using Questionnaire as Proxy to Estimate Obstetric Fistula Prevalence: Results from Demographic and Health Survey. Reproductive Health, 10(1): 14. http://www.reproductive-health-journal.com/content/10/1/14.

T. Mselle and W. Kohi. (2015). Living with Constant Leaking of Urine and Odour: Thematic Analysis of Socio-Cultural Experiences of Women Affected by Obstetric Fistula in Rural Tanzania. BMC Women's Health, 15: 107. DOI 10.1186/s12905-015-0267-1.

Umeora OUJ, Emma-Echiegu NB. (2015). Vesico-Vaginal Fistula in Developing Countries-Time to Turn off the Tap. J Preg Child Health, 2, 120. Doi: 10.4172/2376127X.10 00e120].

UNFPA. (2012). Campaign to End Fistula; Annual Report. Retrieved from http://www .endfistula.org.

WHO. (2015). Obstetric Fistula: Guiding Principles for Clinical Management and Program Development, Editors: Masakhwe, Abawi, Idris Gertiser. Retrieved from http://www.gfmer.ch/fistula/pdf/Obstetricfistula-2015. pdf.

WHO Bulletin. (2010). Mother or Nothing: The Agony of Infertility. Bulletin of the World Health Organization, 88(12): 881-882. Doi:10.2471/BLT.10.011210.

Yeakey MP, Chipeta E, Taulo F, Tsui AO. (2009). The Lived Experience of Malawian Women with Obstetric Fistula. Cult Health Sex, 11: 499-513. Doi: 10.1080/13691050902874777. 
Yenenesh Tadesse. (2014). A Qualitative Study of the Experience of Obstetric Fistula Survivors in Addis Ababa. Ethiopia International Journal of Women's Health, 6: 1033-1043. Doi: 10.2147/IJWH.S68382.

\section{Copyrights}

Copyright for this article is retained by the author(s), with first publication rights granted to the journal.

This is an open-access article distributed under the terms and conditions of the Creative Commons Attribution license (http://creativecommons.org/licenses/by/4.0/). 